This item was submitted to Loughborough's Research Repository by the author.

Items in Figshare are protected by copyright, with all rights reserved, unless otherwise indicated.

\title{
The potential behavioural effect of personal carbon trading: results from an experimental survey
}

PLEASE CITE THE PUBLISHED VERSION

http://dx.doi.org/10.1080/21606544.2013.782471

PUBLISHER

(c) Taylor \& Francis

VERSION

AM (Accepted Manuscript)

LICENCE

CC BY-NC-ND 4.0

\section{REPOSITORY RECORD}

Zanni, Alberto M., Abigail L. Bristow, and Mark Wardman. 2019. "The Potential Behavioural Effect of Personal Carbon Trading: Results from an Experimental Survey”. figshare. https://hdl.handle.net/2134/12914. 
This item was submitted to Loughborough's Institutional Repository (https://dspace.lboro.ac.uk/) by the author and is made available under the following Creative Commons Licence conditions.

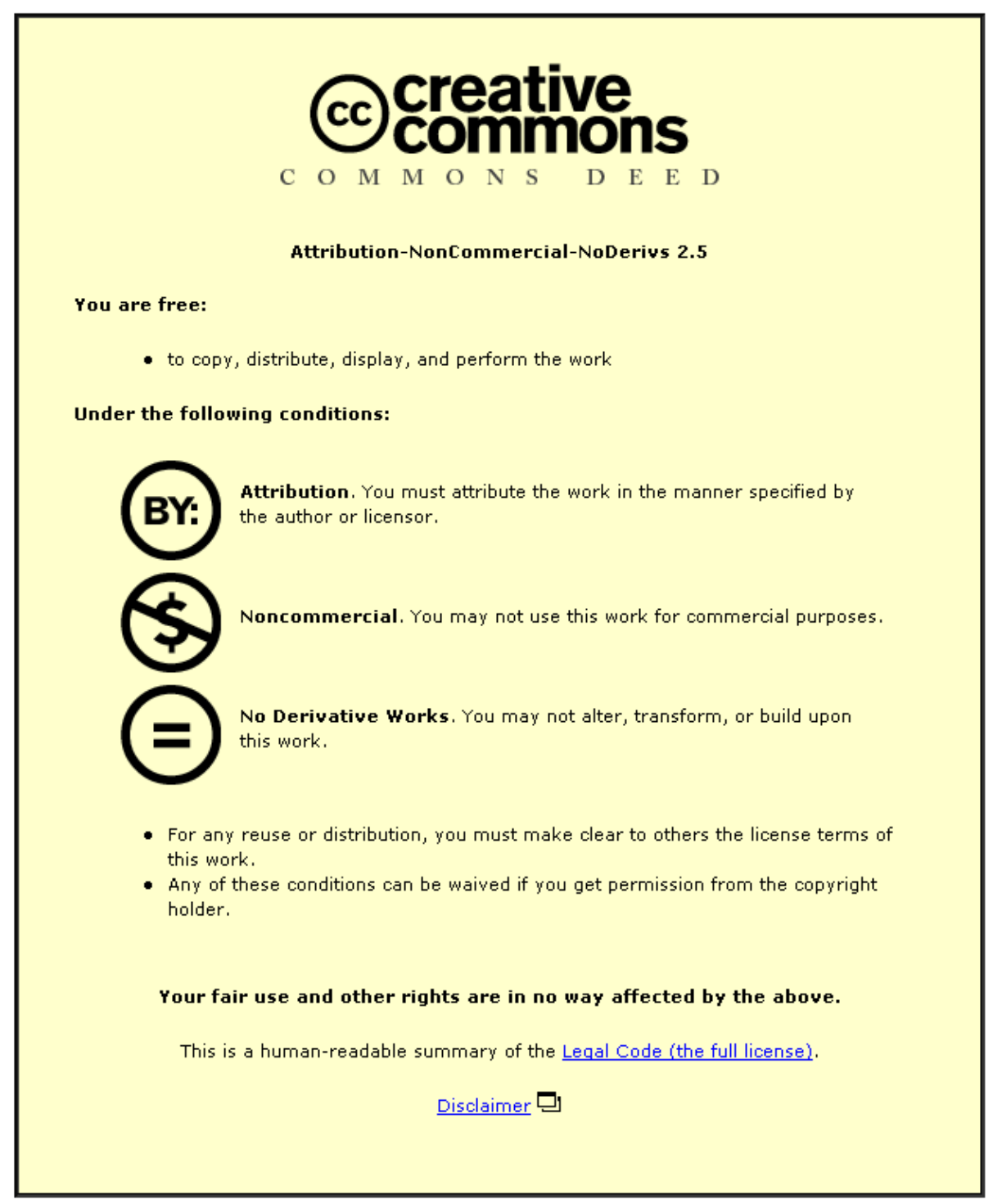

For the full text of this licence, please go to: http://creativecommons.org/licenses/by-nc-nd/2.5/ 


\title{
The potential behavioural effect of personal carbon trading: results from an experimental survey
}

\author{
Alberto M Zanni ${ }^{\mathrm{a}^{*}}$, Abigail L Bristow ${ }^{\mathrm{a}}$ and Mark Wardman ${ }^{\mathrm{b}}$ \\ ${ }^{a}$ Transport Studies Group, School of Civil and Building Engineering, Loughborough University, \\ Loughborough LE11 3TU, UK - " corresponding author,email: a.m.zanni@lboro.ac.uk \\ ${ }^{b}$ Institute for Transport Studies, University of Leeds, 36-40 University Road, Leeds LS2 9JT, UK
}

\begin{abstract}
This paper contributes to the debate on the effectiveness of carbon trading schemes when contrasted with carbon taxes in reducing environmental externalities. An experimental survey explored individual's behavioural response to a personal carbon trading (PCT) scheme, or a carbon tax (CT), both affecting personal transport and domestic energy choices. Responses were two stage, firstly whether to change behaviour or not, and secondly how much to change. Results from the first stage indicate that those on high incomes and car users were less likely to change their behaviour, whilst those who had already changed their behaviour due to concern about climate change, lived in larger households or faced the CT were more likely to change. The second stage revealed fewer significant effects, the impact of already changing behaviour persisted and this case those who faced PCT were likely to make greater changes. Both schemes appear to be capable of reducing individual carbon consumption, however, the evidence on effectiveness of a PCT relative to a simpler $\mathrm{CT}$ is mixed and insufficient to make a strong case for such a complex scheme over a more straightforward tax.
\end{abstract}

Keywords: personal carbon trading, carbon taxes, transport, domestic energy, climate change

JEL codes: H23, Q58, Q48, R48

Word count: 7,217 


\section{Introduction}

Personal Carbon Trading (PCT) schemes have been identified as potential tools to achieve reductions in carbon emissions generated by human behaviour as they directly target individual energy and fuel consumption. PCT schemes are market-based instruments for the control of pollution. They affect the pricing system in order to generate a behavioural switch towards less energy intensive consumption, and hence reduce the level of carbon emissions.

The aim of this paper is to investigate the potential behavioural impact in terms of personal transport and domestic energy usage of a PCT scheme, using a carbon tax (CT) levied on personal consumption as a comparator. We aim to answer the following research questions:

- To what degree are these schemes likely to induce behavioural change in terms of personal transport and domestic energy usage?

- What are the key elements that influence behavioural response?

- Are there any differences in response between a PCT and CT when the monetary incentive is equivalent?

The research reported here addresses these questions through the development and application of an experimental survey instrument that simulates the effect of the schemes on a sample of individuals in accordance with their current carbon consumption. The data obtained enables analysis of a range of potential determinants of behavioural change, 
including socio-economic and attitudinal information, and allows identification of the carbon saving behaviours most likely to be adopted. This study adds to the very limited literature on behavioural response to PCT schemes through the development and application of an experimental survey, which grounds responses in current behaviours and covers a wide range of contextual and behavioural variables. This is, to the best of our knowledge, the first economic study of this type.

This paper is organised as follows. The next section briefly reviews the theory and literature. Section 3 presents the conceptual framework and methodology. Section 4 describes the survey and sample characteristics. Results are presented in section 5, while Section 6 discusses and concludes.

\section{Theory and review of the literature}

Tradable permit schemes find their theoretical roots in the theory of property rights developed by Coase (1960) and subsequently by Dales (1968). These systems set a precise limit to emissions and allow marginal abatement costs to vary across sources. Various types of upstream applications involving the issue and exchange of permits among economic organisations, countries, and energy and fuel producers have been considered and used to control different types of pollution (Benz and Truck 2009; Golombeck and Hoel 2008; Pezzey 2003). Conversely, emission taxes find their theoretical roots in the work of Pigou, which explained the necessity of fixing a tax at the value of the environmental externality in order to attain both the optimal level of production and reduced pollution (Pezzey 2003). Carbon taxes generally take the form of excise taxes on the carbon content of fossil fuels 
and have been proposed and implemented over the years in a number of countries (Aldy et al. 2008; Brannlund and Nordstrom 2004).

Trading schemes have mostly been applied at the upstream level, while carbon taxes concentrating on households and individual consumption are applied in Finland and Denmark (Wier et al. 2005) for example, and in other countries as fuel and energy taxes. Recently attention has been given to the greater involvement of individuals as a way to increase the efficiency of trading schemes and reallocate property rights over the environment. In some proposals, citizens (or environmental organisations) compete with firms in the distribution of allowances with the purpose of retiring permits to pollute from the market (Ahlheim and Schneider 2002; Israel 2007; Malueg and Yates 2006; Rousse 2008). Such systems, however, despite increasing citizens' involvement in the trading of permits, do not directly target individual energy usage.

In the late 1990's Fleming (1997, p. 140) proposed a tradable quota system to provide "a national market for a progressively reduced quantity of carbon units" covering individuals and organisations. This inspired a number of authors to propose a variety of schemes based on this principle including: Personal Carbon Trading (PCT), Personal Carbon Allowances (PCAs), Tradable Energy Quotas (TEQs), Domestic Transferable Permits and Tradable Credit Schemes (Fawcett 2010; Harwatt et al. 2011; Hobbs et al. 2010; Parag et al. 2011; Raux 2004; Yang and Wang 2011). These schemes generally consider a free equal per capita allocation of emissions rights. These rights are then used when purchasing fuel or electricity. Individuals consuming over the allocated amount need to purchase additional rights from those consuming less. Various forms exist with respect, 
for example, to whether individuals can purchase additional rights directly from fuel and energy producers, whether households with children are allocated extra rights, and what sort of emissions are included (for example some schemes cover transport emissions only) (Starkey 2012a) ${ }^{1}$. The PCT design tested in this paper is outlined in detail in section 4.

A number of arguments have been put forward for PCT. We focus here on two key arguments related to the potential of PCT to generate behavioural change. Firstly it is suggested that from an economic efficiency point of view, individual energy consumption reduction appears to be achievable more efficiently downstream, as the market mechanisms allow for the equalisation of the marginal abatement costs for the participants and for a higher degree of flexibility in the switch towards less polluting behaviour (Connor et al. 2008; Joskow et al. 1998). However, PCT schemes are more complex and expensive instruments than taxes, because of the involvement of trading and the necessary transaction costs, and this could potentially reduce behavioural impact and the overall acceptability of such schemes (Bristow et al. 2010).

Secondly, in psychological terms, these schemes are thought to be capable of increasing individual 'engagement' with emission reduction as they are felt as 'immediate' and a more direct way to 'exercise responsibility' (Fleming 1997; Starkey and Anderson 2005). Additionally they provide a vehicle for 'feedback' and 'goal setting' to individuals, the role of which is discussed by Abrahamse et al. (2007), as they transform carbon into a visible resource that can be conserved, budgeted and managed (Capstick and Lewis 2010). A PCT system may also be perceived as giving individuals more choices than

\footnotetext{
${ }^{1}$ These schemes and their characteristics are extensively discussed in two recent papers by Starkey (2012a; b).
} 
a tax as permits can be destroyed (to stop others using them) or retained for future use (Wadud et al. 2008). Most of the points discussed above remain, however, theoretical, as at present no such scheme (at a large scale) is in force. Very few empirical studies have explored the potential behavioural effect of PCT or similar schemes (Capstick and Lewis 2010; Harwatt et al. 2011; Parag et al. 2011; Wallace 2009). These studies vary in terms of the sectors addressed, the range of behaviours (often limited) examined, in some cases price is not included, and current behaviours not always established. This paper reports the results from the first economic study of potential response to PCT (and CT) and adds to existing knowledge by considering a relatively large range of behaviours from transport and domestic energy usage, precisely linking current consumption and potential behavioural change and varying price incentives. This enables us to test the hypothesis that a PCT would lead to greater emissions reductions than a CT with an equivalent price incentive.

\section{Conceptual framework and methodology}

This analysis focuses on emissions produced by domestic energy usage and personal transport, and therefore does not include emissions from the consumption of other goods or services. For simplicity we consider individual (rather than household) decisions.

A simple static theoretical framework is now introduced. Let a consumer's utility function prior to the introduction of the schemes be:

$$
U=u(x, y, e)
$$


Equation (1) shows that this consumer's utility depends on two types of goods, polluting (x), and non-polluting $(y)$ (where $x$ and $y$ are not perfect substitutes in accordance with the information in possession of the agent), and on environmental quality $e$. This function is continuous and strictly quasi-concave in $x$ and $y$ but not in $e$ as it is assumed that individuals may be indifferent to environmental quality ${ }^{2}$. This is reasonable in the context of climate change where the degradation of environmental quality is not always directly felt by individuals (Tjernstrom and Tietenberg 2008). Therefore, we consider perceived rather than observable environmental quality and we do not formalise a precise relationship between consumption (and consequent emissions) and environmental degradation.

The consumption of goods $x$ and $y$ depends on their respective prices and the budget constraint takes the usual form $p_{x} x+p_{y} y=m$ where $p_{x}$ and $p_{y}$ are the prices of the goods $x$ and $y$ respectively, and $m$ represents the consumer's income. If a PCT or CT system comes into force, $t$ is a levy applied to individual consumption exceeding an exogenously fixed value $\bar{x}$ (which represents the allocation and the rebate threshold for PCT and CT, respectively $)^{3}$ so that $p_{x}+t(x-\bar{x})=p_{x}^{s}$, where $p_{x}^{s}$ represents the new price of the polluting goods $x$, while the prices of the non-polluting goods are assumed to remain constant and are therefore normalised to 1 . Then, the consumer's consumption decision depends on the following utility maximisation problem:

\footnotetext{
${ }^{2}$ In the model developed by Bento and Jacobsen (2007) for example, emissions directly reduce consumer utility, while in Kotchen (2009) consumption of private goods affects the public good environment and in this way reduces utility. Here, loss of environmental quality is analysed exclusively through consumers' perception.

${ }^{3}$ The carbon tax system translates into a price increase for all the units of carbon consumed, including those units below the allocation. In a static framework we directly consider the effect of an equal per capita tax rebate and in practice the system only generates a price increase for consumption levels above the allocated amount.
} 
$U=\max _{x, y, e}\left\{u(x, y, e)\left[p_{x}+t(x-\bar{x})\right] x+y=m\right\}$

So, according to equation 2) an above allocation consumer may decide to:

1) continue with consumption of $x$ at the level prior to the introduction of the CT-PCT $(x)$ and pay the augmented price $p_{x}+t(x-\bar{x})=p_{x}^{s}$.

2) reduce consumption of $x$ down to a level where $x=\bar{x}$ (or even beyond, to gain from trading or tax rebate), as below this level the levy is not applied, and pay the price $p_{x}$ as before the application of the scheme.

3) pay a portion of $t\left(x_{i^{-}} \bar{x}\right)$ by partly reducing consumption of $x$, without attaining the level $\bar{x}$.

A below allocation consumer may decide to:

1) continue with consumption of $x$ at the level prior to the introduction of the CT-PCT $(x)$ and obtain the benefit entitlement $t(\bar{x}-x)$ in terms of spare permits to sell or tax rebate.

2) increase consumption towards (or beyond) the allocated amount $\bar{x}$ (the endowment received).

3) further reduce consumption in order to increase the amount of benefit $t(\bar{x}-$ $x)$.

Clearly there is an array of choices at the disposal of both types of consumers which will depend on the utility maximisation problem above. This analysis first considers a discrete choice between reducing (alternative $j$ ) or not reducing (alternative $i$ ) the initial consumption of polluting goods $x$, given the amount of tax/permits. In a Random Utility 
framework (McFadden 1974) this can be modelled as $P($ reduce $)=P\left(\left(V_{j}+\varepsilon_{j}\right)>\left(V_{i}+\varepsilon_{i}\right) ; j \neq\right.$ i) where $V_{i}$ and $V_{j}$ are the consumers' indirect utility functions for the two alternatives $i$ and $j$, and $\varepsilon$ is a stochastic term and, subsequently, a continuous choice (for those who have stated their intention to reduce) over the magnitude of reduction of consumption of $x$. The latter is considered as it is likely that above allocation consumers stating their intention to reduce can maximise their utility in an intermediate situation where they consume less than initially but still above the allocated amount ${ }^{4}$. Importantly, choice is assumed to depend on whether the consumer faces a PCT or CT scheme as well as on attitudinal and socioeconomic characteristics. The analysis allows for the identification of the determinants of choice as well as the amount of carbon consumption $x_{i}$ resulting from the application of the proposed schemes. We will also examine the new composition of the individual carbon consumption (in terms of personal transport and domestic energy usage) and the behaviours most likely to be adopted.

The utility differential may also depend on the perceived change in environmental quality $e$. Consumers reaction to the schemes could simply be based on the value they place on consumption of $x$ (and how much they are prepared to reduce it) if they do not believe that climate change is an issue. Free riding could occur, with individuals believing that their contribution to emission reduction would in any case be minimal. On the other hand, 'public good' and 'environmental concern' effects (Johnson et al. 2006; Kahn 2007), as well as 'warm glow' and 'pure altruism' effects (Laury and Taylor 2008) could have the

\footnotetext{
${ }^{4}$ In Equivalent Loss (EL) terms (Bateman et al. 2005), for above allocation consumers, this amount could therefore be interpreted as a measure of the value consumers attach to their current consumption of polluting (in terms of direct $\mathrm{CO}_{2}$ emission) goods and services which define their 'carbon intensive' lifestyle.
} 
opposite effect. Importantly, increased information provided by the schemes could make certain polluting and non-polluting goods or services almost perfect substitutes, by highlighting 'waste', and it could then be the case that reduced consumption and substitution between $x$ and $y$ could generate the same level of utility.

\section{The schemes, sample and survey}

The PCT scheme used here, illustrated in Table 1 in the Appendix, was based on the UK Royal Society for the Encouragement of Arts, Manufactures and Commerce (RSA) model (2007). The CT instrument was designed to achieve equality of the monetary incentives (excluding distributional impact) between the two schemes, in order to isolate reasons other than price signals for any differences in response.

The UK Department for Environment, Food and Rural Affairs (Defra) 'Act on $\mathrm{CO}_{2}$ ' carbon footprint calculator (Defra 2008), which considers emissions generated by energy and fuel consumption from home usage (heating, lighting and appliances), and for personal transport (including car use and aviation, but excluding land-based forms of public transport) was used to calculate individuals' current carbon consumption. This calculator provided a user-friendly and effective tool to assess respondents' current carbon consumption. The free allocation for PCT and the rebate threshold for CT was set at 4 tonnes $\mathrm{CO}_{2}$ per annum. A tax rebate system rewarded individuals consuming less than the threshold, as does the sale of permits in the case of PCT. The free allocation was below the 4.48 tonnes estimated (at the time of the survey) individual average for domestic and transport emissions in the UK (Defra 2008) and consequently allowed us to simulate a 
scheme designed with the purpose of reducing the allocated amount of emissions per person. Individuals were therefore divided in two main categories, those whose carbon footprint is below 4 tonnes $\mathrm{CO}_{2}$ (below allocation) and those above (above allocation).

A computer assisted survey instrument was developed in order to collect the information necessary for this analysis and the data collection was carried out in May/June 2008 in several locations in the South East of England ${ }^{5}$. The usable sample included responses from 189 individuals. These were almost evenly split between male (51\%) and female (49\%) and across different age bands, with an average household size of 2.6. Approximately half of the sample lived in rented accommodation or with their family, while the rest lived in their own property. $35 \%$ were in full time employment, while $15 \%$ were unemployed. The remaining respondents were in part-time employment, full and parttime education or in retirement (about $10 \%$ for each category). $25 \%$ of the sample did not reveal information about their gross household income, $15 \%$ had an income below $£ 10,000$, $21 \%$ between $£ 10,000$ and $£ 20,000,18 \%$ between $£ 20,000$ and $£ 30,000,12 \%$ from $£ 30,000$ to $£ 50,000$ and $8 \%$ more than $£ 50,000$.

The average carbon footprint was 5.56 tonnes of $\mathrm{CO}_{2}$, with around $60 \%$ of respondents above the free allowance of 4.0 tonnes. Domestic energy accounted for about $65 \%$ of emissions, while the remaining emissions were transport generated (car usage and fly). However, about $25 \%$ of the sample had no transport emissions at all. $35 \%$ of respondents had no car, $46 \%$ one car and $19 \%$ more than one car. The average personal

\footnotetext{
${ }^{5}$ Respondents were recruited on street in four locations in outer London and one in Essex. On average, respondents needed around 45/60 minutes to complete the questionnaire, and were given $£ 10$ as an incentive. A full version of the questionnaire is available upon request.
} 
mileage per year for car users was $3,120^{6}$. The most common domestic energy saving actions already adopted by over $50 \%$ of the sample included turning off lights when leaving a room, using washing machines for full loads only, switching "stand-by" equipment off at the socket, and turning the thermostat down in winter. $25 \%$ said they had reduced their car usage and/or fuel consumption through eco-driving and 15\% stated they had reduced their flying. The least common current actions were those involving the purchase and use of new energy generating technology such as solar panels, micro-wind turbine and ground-source heat pumps.

Respondents first completed the carbon footprint calculator and a set of questions concerning their socioeconomic characteristics, current behaviour in terms of energy usage and transport, and attitudes towards climate change. All respondents were then given a simple explanation of how CT and PCT schemes may work, as well as a predefined list of transport and domestic energy carbon saving actions, see Tables A1 and A2 in the appendix. The list which also contained approximate monetary savings and payoff periods for energy saving and generating devices, was necessary to enable direct calculation of $\mathrm{CO}_{2}$ savings, maintain consistency with the carbon footprint calculator, and avoid respondents suggesting actions outside the scope of the schemes. Carbon savings were indicative and calculated following Defra (2008) and Energy Saving Trust (EST 2008). The list and the subsequent questions enabled us to identify for each individual actions in which they were

\footnotetext{
${ }^{6}$ Population (GLA 2009) and environment (EA 2010) statistics show that females in London in 2008 were slightly more numerous in London (50.5\%) and average household size was 2.6 members. Unemployment rate was $7.2 \%$, average income about $£ 17,000$. Car ownership distribution was as in our sample, while the average mileage was 3,801 . In the same year, about $20 \%$ of London's inhabitants' carbon footprint was generated by transport.
} 
already engaged and those that were simply not relevant (for example reducing car usage was not relevant for non-car owners).

Respondents were then asked how they would respond to a PCT or a CT. Half of the sample faced the CT scheme, the remaining half the PCT scheme. The amount of permits they needed to buy (if above allocation) or could sell (if below) or the amount of tax they had to pay or would receive in rebate form were automatically calculated by multiplying the difference between their carbon footprint and the 4.0 tonnes allocation, and the price per tonne of $\mathrm{CO}_{2}$. Three price levels were equally distributed across the sample: $£ 50, £ 100$ and $£ 250$ per tonne $\mathrm{CO}_{2}$. The rates were generally higher than the central value placed on carbon in the non-traded sector by the UK Department of Energy and Climate Change (DECC) (2009) (set at $£ 50$ for 2008) but were used here (together with an allocation more than $10 \%$ below than the average emission level), because of the relatively low elasticity of demand with respect to energy and fuel price, especially in the short term (Boonekamp 2007; Goodwin et al. 2004; Graham and Glaister 2004), in order to provide a clear price incentive ${ }^{7}$. Respondents were asked, given that amount, to decide between two options: (1) to pay (or receive) the amount and continue with their current carbon consumption, or (2) to engage in carbon saving actions in order to reduce (increase) the amount they had to pay (receive) ${ }^{8}$. This question may be found in Table A3 in the appendix.

\footnotetext{
${ }^{7}$ It is worth observing that a recent study produced evidence of higher price elasticities than previously thought for gas and electricity (Alberini and Filippini 2011), while another claims gasoline is more inelastic than previously thought (Havranek et al. 2012).

${ }^{8}$ Respondents were not given an "opt out" option to surrender all their permits and effectively purchase them from providers as they go, although this would probably have to be an option in any real world implementation, here it would have complicated the experiment.
} 
Respondents who stated an intention to reduce their carbon footprint were then asked to indicate which carbon saving actions they would engage in. The computerised survey showed respondents only actions which were relevant to them and they were not already doing 9 . Respondents were then able to see the corresponding $\mathrm{CO}_{2}$ saving of each selected action and its impact on their initial carbon footprint, as well as the resulting monetary saving (in terms of permit/tax over a year) ${ }^{10}$.

\section{Empirical models and results}

\subsection{Sample differences and variable definitions}

Before introducing the results of the econometric analysis of choice data we provide some summary information. First of all, as one of the objectives of our paper is to explore the PCT/CT differential in behavioural impact, it is useful to discuss any differences between the respondents who received PCT and those who received CT. We therefore need to assess whether differences in behaviour may be related to particular characteristics of the two subsamples rather than a genuinely differential response to the two schemes. A comparison of the mean for a number of sample characteristics revealed that the two sub-samples significantly differed for two characteristics only. These were the household size (which was higher for respondents who received PCT, $p=0.04$ ) and the perceived capacity to save

\footnotetext{
${ }^{9}$ Exceptions to this were measures already engaged in but where more could be done, for example, reducing car use.

${ }^{10}$ Please note that investment and payoff period figures for energy saving devices were given to respondents for information only. In our simple theoretical approach their impact on disposable income is not considered, and consequently the calculated tax/permit saving figures were also not affected.
} 
carbon from domestic energy usage (also higher for respondents who received PCT, $p=0.00)$. All other characteristics including initial carbon footprint and proportion of below and above allocation respondents were not significantly different. However, the random distribution of carbon price levels across the sample also generated a significant difference with respondents who received CT facing a lower price per tonne, and, consequently a lower total amount of cost/benefit ( $p=0.08$ and $p=0.05$, respectively). These differences were tested in the empirical analysis.

Table 1 lists the variables considered to be potential determinants of respondents' choices and used in this analysis. These include price levels, respondents' current transport usage, home tenure, environmental attitudes, demographic and socio-economic characteristics and perceived abatement costs. Two price variables were considered, the cost (or benefit) per unit tonne of $\mathrm{CO}_{2}$ (PriceU), and the total cost (PriceT), price per tonne multiplied by difference between respondents' initial footprint and free allocation). Both were hypothesised to have an effect on respondents' decisions. Differences between the respondents who faced $\mathrm{CT}$ and those who face PCT were captured by the variable TAXPCT

\section{[TABLE 1 GOES HERE]}

\subsection{Discrete choice - Would you reduce?}

The majority of respondents, $80 \%$ in the case of CT and $72 \%$ in the case of PCT, stated an intention to reduce their carbon footprint given the conditions of the two schemes. As indicated in section 3 we are considering a discrete response of the form $P($ reduce $)=$ $P((V j+\varepsilon j)>(V i+\varepsilon i) ; j \neq i)$. If we consider $V_{j}=\beta X_{j}$, where $\beta$ is a vector of parameters, we can 
estimate the probability of choosing to reduce carbon consumption using the binary logit probability function:

$$
P_{j}=\frac{\exp \left(\beta^{\prime} X_{j}\right)}{1+\exp \left(\beta^{\prime} X_{j}\right)}
$$

An interaction term was specified between price (both total and per unit) and above/below allocation to distinguish between money gains and losses. Table 2 shows the binary logit models estimated, Model 1 uses PriceT and Model 2 PriceU.

\section{[TABLE 2 GOES HERE]}

Table 2 shows that the models are broadly similar, in terms of general performance, the model with marginal rather than total cost/benefit performs better as it has a higher McFadden $\mathrm{R}^{2}$. Here we discuss those variables found to have a significant influence on response. Respondents living in larger households, not using a car and in employment were more likely to reduce their carbon footprint given the conditions of the schemes as did those who had already made changes to their transport and domestic energy choices (most strongly where climate change is a reason for changing), had a lower perceived importance of time constraints (to engage in carbon saving actions) and, surprisingly, those with higher perceived cost barriers to carbon saving behaviour. Additionally in Model 2 those whose footprint was higher than expected were more likely to change. In Model 1 those aged 30 to 40 were less likely to change than those aged over 60 , but this is only significant at $90 \%$ and otherwise age was not an influential variable on response. These findings are largely intuitive. Though the household size effect was not anticipated, it might be expected that larger households on average consume more and therefore have greater available opportunity to reduce. Finally, those on higher incomes were less likely to change in 
response to the price offered, and those who were offered at CT were more likely to change their behaviour than those offered the PCT.

Price (both in its marginal and total form, with the former having a more significant impact) had a significant effect. In order to understand whether this effect was different depending on whether the respondents were above or below allocation, further analysis was carried out on the interaction term employing a graphical technique recently proposed by Greene (2010). This allows for the analysis of interactions in single index logit models overcoming the issues linked to the interpretation of the interaction coefficient (and the corresponding partial effect) first highlighted by Ai and Norton (2003).

Firstly, it is necessary to calculate the partial effect of the interaction terms. For the case of a logit model where one continuous variable and a dummy are interacted, the partial effect of the interaction term is the discrete difference (with respect to $x_{2}$ ) of the single derivative (with respect to $x_{1}$ ) (Ai and Norton 2003; Norton et al. 2004):

$$
\begin{aligned}
& \frac{\Delta \frac{\partial F(u)}{\partial x_{1}}}{\Delta x_{2}}=\left(\beta_{1}+\beta_{12}\right)\left\{F\left[\left(\beta_{1}+\beta_{12}\right) x_{1}+\beta_{2}+X \beta\right] \times\left(1-F\left[\left(\beta_{1}+\beta_{12}\right) x_{1}+\beta_{2}+X \beta\right]\right\}\right. \\
& -\beta_{1}\left\{F\left(\beta_{1} x_{1}+X \beta\right)\left[1-F\left(\beta_{1} x_{1}+X \beta\right]\right\}\right.
\end{aligned}
$$

In Equation 4), where $\beta$ are the estimated parameters, $F$ is the standard logit cumulative distribution function, $x_{1}$ and $x_{2}$ the two interacting variables, and $X$ the remaining covariates (at their means). Greene (2010), unlike Ai and Norton (2003), does 
not perform a test of statistical significance over the partial effect but uses it to graphically analyse the interaction effect as in the following figure ${ }^{11}$ :

\section{[FIGURE 1 GOES HERE]}

Figure 1 shows the difference in terms of reaction to total price between the two classes of respondents. Partial effects ( $Y$ axis) are plotted against PriceT ( $X$ axis). The distance between the two lines can be interpreted as the interaction effect. Total price has a higher impact on the choice outcome for above allocation respondents (the dotted line), indicating that monetary losses are more important than gains in determining the choice outcome. The importance of losses in determining the probability to reduce increases with total price up to a value of about $£ 1,500$ per year, to become fairly steady thereafter. For below allocation respondents, intuitively, the effect of total gain is reversed and higher amounts have a diminishing effect on the choice outcome, as at a higher price of carbon these respondents will receive more before they make any changes ${ }^{12}$.

\section{[FIGURE 2 GOES HERE]}

Figure 2 shows that the effect of PriceU is also higher for above allocation respondents, especially at higher prices per unit. The effect of price per unit of $\mathrm{CO}_{2}$ has an upward impact on the choice outcome for above allocation respondents, who are therefore

\footnotetext{
${ }^{11}$ The analysis was carried out using LIMDEP 9.0. Communication with William Greene was instrumental in the comprehension and preparation of the relevant codes.

${ }^{12}$ Please note that the maximum amount of total gain for below allocation respondents was $£ 842$ pounds, while the corresponding maximum total cost for above allocation respondents was $£ 2610$. The ranges are obviously different between the two classes of respondents as carbon footprint figures lies in the range [0 $\infty$ ], with 4 being the allocation. The plot in Figure 2 projects therefore the partial effect for higher figures for below allocation respondents in order to compare the two classes of respondents at all values.
} 
more likely to reduce their carbon consumption when the price per Tonne is higher. A similar but weaker trend is observed for below allocation respondents.

The models presented earlier in Table 2 showed that respondents facing a CT were more likely to state their willingness to reduce. Here we examine whether this is determined by differences in the price levels or by a genuinely different reaction the two schemes. Models considering the interaction of CT/PCT with PriceT or U were estimated, and the partial effect of the interaction terms was calculated as in Equation 4). Figure 3 graphically illustrates the case of PriceT.

\section{[FIGURE 3 GOES HERE]}

Figure 3 shows that the probability to reduce emissions increases with price under both schemes. The higher partial effect for CT indicates that at the same price levels respondents who received CT were indeed more likely to reduce. This differential diminishes as total cost (gain) increases. A similar result is also obtained when unit rather than total price per tonne of $\mathrm{CO}_{2}$ are considered as shown below in Figure $4^{13}$.

\section{[FIGURE 4 GOES HERE]}

\footnotetext{
${ }^{13}$ There were two other significant differences between the sub-samples, one of these perceived ability to save carbon at home was not significant in the models and therefore not pursued further. Household size was higher for those receiving PCT therefore an interaction between Household size and TAXPCT was explored using the same graphical method. This showed that the effect of tax on the choice outcome was not dependent on household size as the partial effect for CT was higher than PCT at all household sizes.
} 


\subsection{Continuous choice - If yes, how much would you reduce?}

Table 3 shows average savings for those who would change their behaviour of $13.9 \%$ for

CT and $18.6 \%$ for PCT. Across the whole sample (including those who do not change) savings are $10.9 \%(\mathrm{CT})$ and $13.3 \%(\mathrm{PCT})$. End of experiment carbon footprint figures were slightly above 5 tonnes for CT respondents and 4.75 tonnes for PCT respondents. Generally, domestic energy savings were higher than in transport (the two figures are significantly different, $p=0.01$ ).

\section{[TABLE 3 GOES HERE]}

Respondents were given the opportunity to select actions to reduce their footprint and the amount of tax or permits to buy (or increase permits to sell). Overall, about two thirds of car users said they would reduce their annual mileage (by about 1,100 miles, on average) and adopt a more fuel efficient driving style ${ }^{14}$. Conversely, there was a resistance to reducing the number of flights, especially long haul international ones, while some respondents did manifest a willingness to substitute flights with trains for domestic trips. In terms of domestic energy usage, setting the thermostat at a lower temperature in winter and switching appliances off at the socket to avoid stand-by were the most popular energy saving actions at home, with more than half of the respondents choosing these actions to reduce their footprint. The least popular actions were those involving the purchase and installation of energy saving devices, in particular solar panel and micro wind turbines.

\footnotetext{
${ }^{14}$ Supplementary questions (with no consequences on carbon and payments levels) asked respondents to indicate the way they intended to reduce their car usage and fuel consumption, and the most popular actions were: cycling and walking more, increasing usage of public transport, driving with a smoother style, improving car maintenance and, perhaps surprisingly, reducing speed on motorways.
} 
Among these, switching to a more efficient boiler (condensing) was the most popular (about 40\%).

Analysis includes only those respondents who stated the intention to reduce their carbon footprint, and who were therefore shown the list of carbon saving actions (see Section 4 and Table A2 in the Appendix for details). The dependent variable here was the level of $\mathrm{CO}_{2}$ saving expressed as a proportion of the respondents' initial carbon footprint. Results in Table 4 below were obtained with Generalised Least Squares (GLS). A normal linear model was employed, despite the proportional nature of the dependent variable, for simplicity and to allow for a more straightforward exploration of interaction effects. Data were also analysed employing the more appropriate generalised linear (quasi-likelihood regression) model (Papke and Wooldridge 1996) and the results did not substantially differ.

\section{[TABLE 4 GOES HERE]}

The model in Table 4 shows a limited number of coefficients that significantly influence the magnitude of savings, and this is also reflected in the relatively low $\mathrm{R}^{2}$. The small size of this sample may have played a role in determining this. The significant coefficients show that respondents in education, those with the highest perceived ability to save from domestic energy usage, and those who had already made changes to their consumption, motivated by environment concerns, were those who saved most with respect to their initial carbon footprint, all intuitively logical effects. The same applied to respondents who live in their own property, in comparison with those who rent. The latter was expected as home owners have greater opportunities than tenants to adopt carbon saving behaviour and, especially, technology at domestic level. However, surprisingly, 
carbon savings were also higher for respondents who thought their carbon footprint was lower than expected and, unlike the case of whether to change or not, for respondents living in smaller households.

Table 4 also reports the interaction between the monetary variable and the condition of below/above allocation. The estimate for Price_T shows that the total cost (gain) is not significant for above allocation respondents. In order to detect the effect on below allocation respondents a further test of significance was carried out on the hypothesis of the sum of the two coefficients $\beta$ Price_T+ $\beta$ Price_Tx Blwabv being equal to zero (see for example De Mel et al. 2009). This test $(p=0.038)$ revealed that, in contrast to the previous case, total gain had an effect on below allocation respondents, with these respondents saving more when the total gain was higher.

Marginal prices had an impact on the initial decision of whether to reduce or not, but did not significantly affect the magnitude of $\mathrm{CO}_{2}$ savings. The lack of significance of the marginal monetary variables, albeit surprising, may suggest that respondents did not simply tick actions in order to decrease (increase) their monetary sacrifice (benefit), but carefully considered what was feasible according to their personal situation and perceived ability to engage in carbon saving actions. This argument is supported by the finding that 14 respondents who chose to reduce did not select any of the carbon saving options shown to them. Most of these respondents commented that although they wanted to reduce their carbon emissions the actions shown to them were not feasible for various reasons. This 
suggests that the respondents were fully engaged with the survey and making realistic decisions.

Finally, in both variants of the model the TAX/PCT variable is significant showing that the difference in saving figures between the two schemes highlighted in Table 3, with respondents facing a PCT saving more than those facing CT, is statistically significant. This variable was again interacted with those variables whose means were significantly different between the two sub-samples. These were total cost (gain), household size, perceived ability to save from transport, and perceived cost barriers. All of these but the last one were higher for respondents who received PCT. The results indicate that differences between saving figures for $\mathrm{CT}$ and PCT were not a consequence of the differences between the two sub-samples as the corresponding interaction effects were not significant.

\section{Discussion and conclusions}

This discussion relates the findings to the research questions raised in the introduction.

The first question related to the extent of any behavioural change induced by the PCT and CT. We find that for the schemes presented here reported $\mathrm{CO}_{2}$ savings were for the overall sample around $10.9 \%$ for CT and $13.3 \%$ for PCT, respectively, with figures up to $18.6 \%$ for those who change their behaviour. These results are generally in line with ranges reported elsewhere in response to hypothetical measures(Brannlund and Nordstrom 2004; Lundin 2001; Parag et al. 2011; Tight et al. 2007), suggesting perhaps that there is a limit at around $20 \%$ for short-term reductions in carbon consumption. 
In terms of specific carbon saving actions our findings show that respondents perceive saving energy from home easier than from personal transport. This was confirmed by our further analysis as savings made in domestic energy usage were significantly higher than in transport. Respondents showed willingness to reduce car usage and adopt a more fuel efficient driving style. However, a resistance to reduce the number of flights (especially long-haul) was observed. In common with other examples in the literature (Dresner and Ekins 2006; Poortinga et al. 2003; Scarpa and Willis 2010) a certain scepticism was observed for unfamiliar domestic energy technologies (in particular electricity generating devices like micro-wind turbine, solar panels, and ground source heat-pumps) requiring a considerable initial investment and uncertain pay-off period. Improved home insulation appeared to be more acceptable, also in line with the findings of other recent studies (Banfi et al. 2008) as well as the purchase of condensing boilers. In general, the most popular energy saving actions were those requiring only minor adjustments to comfort and/or behaviour not requiring a considerable reduction in comfort and deep behavioural change. A significant effort in terms of information over the benefits of the most recent systems, and provision of grants to help initial investments, may therefore be required to increase their acceptability and usage.

The second research question sought to determine the key elements that influence behavioural response. Price per unit is a key determinant of the initial choice of whether to change behaviour or not and has a greater effect for those who would pay than those who would gain. Apart from the dichotomy loss/gain already widely documented in the literature, there may be an issue of trust for such novel schemes where respondents do not 
believe that a permit or tax scheme will actually deliver the monetary gain specified and therefore their choices are based on other factors. However, total gain was significant for below allocation respondents when analysing the magnitude of change, while marginal cost and gain were not. The relatively weak influence of price on the level of reduction may be because these decisions, in such an experimental setting, were largely affected by considerations of feasibility and other constraints affecting respondents perceived abatement costs. Discussion with respondents during the survey revealed that a number of them were not previously aware of the potential saving (both in financial and emissions terms) behind certain behavioural changes. Increased information, independent from price effects, may therefore have played a role here (as would be the case in a real world implementation).

The analysis of the decision to reduce or not to reduce revealed a number of other influential variables. An income effect is detected indicating a greater likelihood of changing behaviour for the lowest income band with respect to the highest. The literature generally reports that carbon footprint increases with income (Druckman and Jackson 2009). Our results suggest that the most affluent people are also less willing to change their behaviour. Other socio-economic characteristics have a positive effect: not using a car, being in employment and household size. Additionally those who reported they had already made changes to reduce energy use were more likely to change their behaviour here. This effect is particularly strong, as expected, for those who had made changes explicitly to reduce their carbon emissions. Those who perceived their carbon footprint was higher than expected, who perceived lower time barriers to change and higher cost barriers were also 
more likely to change. While the positive effect on those with a higher carbon footprint than expected confirms the potential of the schemes to increase visibility of current consumption, it is possible that for the latter respondents the increased price was enough to counterbalance their price sensitivity to perceived costs to adopt less carbon intensive behaviour.

The regression model looking at reduction levels had a relatively poor fit and relatively few significant variables. However, those in education and who perceive it to be easy to make energy savings in the home, saved more. The same applied those who had already made changes for reasons relating to climate change. Expectedly, those who rent saved less than home owners. Differences between the results from the analysis of the two questions, in particular the different effect of price, may have been due to different framing effects. In the first one respondents were simply asked to state the intention to reduce or not given a payment linked to their current carbon footprint. In the second one, respondents were asked to precisely state the way they intend to reduce by selecting carbon saving actions among a pre-defined list.

Finally, the evidence is mixed on whether change in domestic energy and personal transport choices may differ between a CT and PCT schemes. The fact of facing a CT scheme appeared to be a determinant of the stated intention to reduce. However, when specific carbon saving actions were considered, PCT generated higher levels of saving for those who changed their behaviour. While in this experimental setting the visibility of carbon consumption was the same across the two schemes (i.e the way carbon footprint was 
calculated and saving figures presented), the capacity of PCT to better link money and carbon, as observed in the introduction, may have played a role here, although this was not further supported by the significance of the marginal monetary variable. A stronger individual 'engagement' with emission reduction, a sense of immediacy, as well as the perception of PCT being a more direct way to 'exercise responsibility' may have influenced the response.

This study is a first step in assessing the way individual consumers could react to PCT schemes and the consequent potential levels of carbon saving. An experimental survey instrument, considering a relatively large number of possible behavioural changes, was necessary to analyse such a novel and untested scheme. A precise link between simulated scheme and respondents' current carbon consumption and situation was set up in order to reduce the hypothetical bias and results have certainly shown this was the case. The analysis has provided some interesting and useful insights into people's preferences and possible reaction to the scheme. Consideration of the potential cost of the application of the two schemes and whether the achievable $\mathrm{CO}_{2}$ emissions savings would represent an efficient use of resources was beyond the scope of this study. There remain other unanswered questions on the way consumers would effectively react to these schemes if in place, in particular their approach to trading permits, and further work on PCT schemes should aim to consider a dynamic rather than static setting and effectively simulate the functioning of the scheme (i.e. trading between agents) over a larger sample of individuals. 


\section{Reference list}

Abrahamse, W., L. Steg, C. Vlek and T. Rothengatter. 2007. The effect of tailored information, goal setting and tailored feedback on household energy use, energyrelated behaviours, and behavioural antecedents. Journal of Environmental Psychology 27: 265-76.

Ahlheim, M. and F. Schneider. 2002. Allowing for household preferences in emission trading. Environmental and Resource Economics 21: 317-42.

$\mathrm{Ai}, \mathrm{C}$. and E.C. Norton. 2003. Interaction terms in logit and probit models. Economics Letters 80: 123-29.

Alberini, A. and M. Filippini. 2011. Response of residential electricity demand to price: The effect of measurement error. Energy Economics 33, no 5: 889-95.

Aldy, J.E., E. Ley and I.W.H. Parry. 2008. A tax-based approach to slowing global climate change. National Tax Journal LXI: 493-517.

Banfi, S., M. Farsi, M. Filippini and M. Jakob. 2008. Willingness to pay for energy-saving measures in residential building. Energy Economics 30: 503-16.

Bateman, I., D. Kaheman, A. Munro, C. Starmer and R. Sugden. 2005. Testing competing models of loss aversion: An adversarial collaboration. Journal of Public Economics 89: $1561-80$.

Bento, A.M. and M. Jacobsen. 2007. Ricardian rents, environmental hypothesis and the 'double-dividend' hypothesis. Journal of Environmental Economics and Management 53: 17-31.

Benz, E. and S. Truck. 2009. Modelling the price dynamics of $\mathrm{co}_{2}$ emission allowances. Energy Economics 31: 4-15.

Boonekamp, P.G.M. 2007. Price elasticities, policy measures and actual developments in household energy consumption - a bottom up analysis for the netherlands. Energy Economics 29: 133-57.

Brannlund, R. and J. Nordstrom. 2004. Carbon tax simulation using a household demand model. European economic review 48: 211-33.

Bristow, A.L., M. Wardman, A.M. Zanni and V.P.K. Chintakayala. 2010. Public acceptability of personal carbon trading and carbon taxes. Ecological Economics 69: 1824-37.

Capstick, S.B. and A. Lewis. 2010. Effects of personal carbon allowances on decisionmaking: Evidence from an experimental simulation. Climate Policy 10: 369-84.

Coase, R.A. 1960. The problem of social cost. Journal of Law and Economics 3: 1-44.

Connor, J.D., J. Ward, C. Clifton, W. Proctor and D. Hatton MacDonald. 2008. Designing, testing and implementing a trial dryland salinity credit trade scheme. Ecological Economics: 574-88. 
Dales, J. 1968. Land, water and ownership. Canadian Journal of Economics 1: 791-804.

De Mel, S., D. McKenzie and C. Woodruff. 2009. Are women more credit constrained? Experimental evidence on gender and microenterprises returns. American Economic Journal: Applied Economics 1: 1-32.

DECC. 2009. Analytical annex. The uk low carbon transition plan: Department of Energy and Climate Change, HM Government, London.

Defra. 2008. Act on $\mathrm{co}_{2}$ calculator: Public trial version. Data, methodology and assumptions paper. London: Department for Environment, Food and Rural Affairs (Defra).

Dresner, S. and P. Ekins. 2006. Economic instruments to improve uk home energy efficiency without negative social impacts. Fiscal Studies 27: 47-74.

Druckman, A. and T. Jackson. 2009. The carbon footprint of uk households 1990-2004: A socio-economically disaggregated, quasi-multi-regional input-output model. Ecological Economics 68, no 7: 2066-77.

EA. 2010. State of the environment in london: Environment Agency.

EST. 2008. Energy saving assumptions. London: Energy Saving Trust (EST).

Fawcett, T. 2010. Personal carbon trading: A policy ahead of its time? Energy Policy 38: 6868-76.

Fleming, D. 1997. Tradable quotas: Using information technology to cap national carbon emissions. European Environment 7: 139-48.

GLA. 2009. Focus on london 2009. London: Greater London Authority.

Golombeck, R. and M. Hoel. 2008. Endogenous technology and tradable emission quotas. Resource and Energy Economics 30: 197-208.

Goodwin, P., J. Dargay and M. Hanly. 2004. Elasticities of road traffic and fuel consumption with respect to price and income: A review. Transport Reviews 24, no 3: $275-92$.

Graham, D.J. and S. Glaister. 2004. Road traffic demand elasticity estimates: A review. Transport Reviews 24, no 3: 261-74.

Greene, W. 2010. Testing hypotheses about interaction terms in nonlinear models. Economics Letters 107: 291-96.

Harwatt, H., M. Tight, A. Bristow and A. Guhnemann. 2011. Public response to personal carbon trading and fuel price increases in the transport sector: Empirical findings from the uk. European Transport \Trasporti Europei 47: 47-70.

Havranek, T., Z. Irsova and K. Janda. 2012. Demand for gasoline is more price-inelastic than commonly thought. Energy Economics 34, no 1: 201-07.

Hobbs, B.F., J. Bushnell and F.A. Wolak. 2010. Upstream vs. Downstream co2 trading: A comparison for the electricity context. Energy Policy 38: 3632-43.

Israel, D. 2007. Environmental participation in us sulfur allowance auction. Environmental and Resource Economics 38: 373-90.

Johnson, L.T., E.E. Rustrom and J.G. George. 2006. Income distribution preferences and regulatory changes in social dilemmas. Journal of Economic Behaviour \& Organization 61: 181-98.

Joskow, P., R. Schmalense and E. Bailey. 1998. The market for sulphure dioxide emissions. The American Economic Review 88: 669-85.

Kahn, M. 2007. Do greens drive hummers of hybrid? Environmental ideology as a determinant of consumer choice. Journal of Environmental Economics and Management 54: 129-45. 
Kotchen, M.J. 2009. Voluntary provision of public goods for bads: A theory of environmental offsets. The Economic Journal 119: 883-99.

Laury, S.K. and L.O. Taylor. 2008. Altruism spillovers: Are behaviours in context-free experiments predictive of altruism toward a naturally occurring public-good? Journal of Economic Behaviour \& Organization 65: 9-29.

Lundin, D. 2001. Welfare-improving carbon dioxide tax reform taking externality and location into account. International Tax and Public Finance 8: 815-35.

Malueg, D.A. and A.J. Yates. 2006. Citizen participation in pollution permit markets. Journal of Environmental Economics and Management 51: 205-17.

McFadden, D. 1974. Conditional logit analysis of qualitative choice behaviour. In Frontiers of econometrics, ed. Zarembka, P, 105-42. New York: Academic Press.

Norton, E.C., H. Wang and C. Ai. 2004. Computing interaction effects and standard errors in logit and probit models. The Stata Journal 4: 154-67.

Papke, L.E. and M. Wooldridge. 1996. Econometric methods for fractional response variables with an application to 401(k) plan participation rates. Journal of Applied Econometrics 11: 619-32.

Parag, Y., S. Capstick and W. Poortinga. 2011. Policy attribute framing: A comparison between three policy instruments for personal emissions reduction. Journal of Policy Analysis and Management 30, no 4: 889-905.

Pezzey, J.C.V. 2003. Emission taxes and tradeable permits. A comparison of views on long-run efficiency. Environmental and Resource Economics 26: 329-42.

Poortinga, W., L. Steg, C. Vlek and G. Wiersma. 2003. Household preference for energysaving measures: A conjoint analysis. Journal of Economic Psychology 24: 49-64.

Raux, C. 2004. The use of transferable permits in transport policy. Transportation Research Part D 9: 185-97.

Rousse, O. 2008. Environmental and economic benefits resulting from citizens' participation in $\mathrm{CO}_{2}$ emissions trading: An efficient alternative solution to the voluntary compensation of $\mathrm{Co}_{2}$ emissions. Energy Policy 36: 388-97.

RSA. 2007. Personal carbon trading: The idea, its development and design. London The Royal Society of Arts (RSA).

Scarpa, R. and K.G. Willis. 2010. Willingness-to-pay for renewable energy: Primary and discretionary choice of british households' for micro-generation technologies. Energy Economics 32: 129-36.

Starkey, R. 2012a. Personal carbon trading: A critical survey. Part 1: Equity. Ecological Economics 73: 7-18.

Starkey, R. 2012b. Personal carbon trading: A critical survey. Part 2: Efficiency and effectiveness. Ecological Economics 73: 19-28.

Starkey, R. and K. Anderson. 2005. Domestic tradable quotas: A policy instrument for reducing greenhouse gas emissions from energy use. Norwich: Tyndall Centre for Climate Change Research - Technical Report 39.

Tight, M.R., A. Vicat, A.L. Bristow, A. Pridmore and A.D. May. 2007. An exploration of household responses to personal travel carbon reduction targets. International Journal of Sustainable Transportation 1: 143-59.

Tjernstrom, E. and T. Tietenberg. 2008. Do differences in attitudes explain differences in national climate change policies? Ecological Economics 65: 315-24. 
Wadud, Z., R.B. Noland and D.J. Graham. 2008. Equity analysis of personal tradable carbon permits for the road transport sector. Environmental Science \& Policy 11: $533-44$.

Wallace, A.A. 2009. Reducing carbon emissions by households: The effects of footprinting and personal allowances. PhD Thesis, De Montfort University.

Wier, M., K. Birr-Pedersen, H.K. Jacobsen and J. Klok. 2005. Are $\mathrm{co}_{2}$ taxes regressive? Evidence from the danish experience. Ecological Economics 52: 239-51.

Yang, H. and X. Wang. 2011. Managing network mobility with tradable credits. Transportation Research Part B 45: 580-94. 


\section{Appendix}

Table A1. Description of the two schemes as they appeared to our study participants

\section{INTRODUCTION TO CARBON TAX}

This would be a tax on all purchases of energy that contribute to climate change. This would include:

- Gas

- Electricity

- Petrol / diesel

- Heating oil, coal or wood.

This would increase the cost of all energy forms that contain carbon.

This higher price would reflect the cost to the environment and would make us think about:

- Conserving energy

- Changing what we do - installing or buying solar or wind power, using public transport instead of driving

Such a tax would generate money for the Government. This money could be used for a range of purposes:

- Reducing other taxes, such as income tax

- Investing in energy saving technologies or options, such as public transport or renewable energy.

- Measures to help individuals to change their behaviour or reduce consumption, home insulation grants, public transport etc.

- Give some money back to individuals directly.

TO SUM UP:

Everyone pays the same rate of tax regardless of income - in the same way as current purchase taxes.

The design could include lump sum payments, cuts in other taxes or expenditure on carbon reduction measures.

In this example we want you to consider that all carbon is taxed and the Government gives a tax refund up to the average carbon consumption. This means that only above average consumers pay more.

\section{INTRODUCTION TO PERSONAL CARBON TRADING}

The purchase and use of energy that contributes to climate change, gas, electricity, petrol /diesel, coal / oil / wood would require you to provide carbon permits for that amount of energy.

We are asking you to consider only your personal travel including commuting to a place of work but not business travel. Businesses would be subject to a similar scheme to encourage the reduction of emissions.

\section{Allowance}

All adults would be given an equal and free allowance of permits. Initially, in the first year this would be based on average carbon consumption. After that the allowance would gradually reduce to encourage reductions in carbon use.

\section{Functioning}

Every time you buy petrol /diesel or pay a gas or electricity bill the relevant number of permits would be deducted from your account.

If you do not have enough permits for a purchase you will need to buy additional ones

If you do not use all of your permit allowance you can sell them for money.

The principle is that people who need extra permits may buy them from people who have some in excess, and viceversa.

The aim would be to reduce emissions of carbon. A PCT (Personal Carbon Trading) would encourage people to do this to avoid having to buy permits or to allow them to sell spare permits.

We are now going to describe how a scheme might work and ask you about your response to it. Adults would receive an equal allowance of 4.0 tonnes of $\mathrm{CO}_{2}$.

Those with children would receive an additional, smaller allowance for each child under 18 . 
Table A2. Carbon Saving Actions

\begin{tabular}{|c|c|c|c|}
\hline $\begin{array}{l}\text { Carbon Saving Actions } \\
\text { Information on savings and costs }\end{array}$ & $\begin{array}{c}\mathrm{CO}_{2} \\
\text { (Tonnes) }\end{array}$ & $\begin{array}{l}\text { Purchase cost } \\
(£)+\text { payback }\end{array}$ & $\begin{array}{l}\text { Approximate } \\
\text { Saving per } \\
\text { year } \\
\text { (£) }\end{array}$ \\
\hline \multicolumn{4}{|l|}{ Transport } \\
\hline Reduce your car usage by ....miles per year & $\begin{array}{c}0.03 \mathrm{t} \\
\text { per/100 miles }\end{array}$ & nothing & $\begin{array}{c}14 \\
\mathrm{p} / 100 \text { miles }\end{array}$ \\
\hline $\begin{array}{l}\text { Reduce your car fuel consumption by around } 10 \% \\
\text { (eco-driving, no aircon, } 60 \mathrm{mph} \text { on m'way, etc.) } \\
\text { (saving for average mileage) }\end{array}$ & $\begin{array}{c}0.3 \mathrm{t} \\
\text { per/year }\end{array}$ & nothing & 125 \\
\hline $\begin{array}{l}\text { Buy a more fuel efficient car - (saving for average } \\
\text { mileage) }\end{array}$ & $\begin{array}{c}0.6 \mathrm{t} \\
\text { per/year }\end{array}$ & $\begin{array}{l}\text { depending on } \\
\text { model }\end{array}$ & 250 \\
\hline $\begin{array}{l}\text { Reduce the number of domestic return flights (UK) } \\
\text { by...per year }\end{array}$ & $\begin{array}{c}0.15 \mathrm{t} \\
\text { per/return fight }\end{array}$ & nothing & price of ticket \\
\hline $\begin{array}{l}\text { Reduce the number of short haul international return } \\
\text { flights (Europe) by...per year }\end{array}$ & $\begin{array}{c}0.3 \mathrm{t} \\
\text { per/return fight }\end{array}$ & nothing & price of ticket \\
\hline $\begin{array}{l}\text { Reduce the number of long haul international } \\
\text { (Intercontinental) return flights by...per year }\end{array}$ & $\begin{array}{c}1.4 \mathrm{t} \\
\text { per/return fight }\end{array}$ & nothing & price of ticket \\
\hline \multicolumn{4}{|l|}{ Energy usage } \\
\hline $\begin{array}{l}\text { Turn your thermostat down by ... degrees in winter - } \\
\text { (saving per year per household) }\end{array}$ & $\begin{array}{l}0.3 \mathrm{t} \text { per/degree } \\
\text { Celsius }\end{array}$ & nothing & $30 / 60$ \\
\hline $\begin{array}{l}\text { Switch electrical equipment off at the socket to avoid } \\
\text { "stand by" - (saving per year per household) }\end{array}$ & $\begin{array}{c}0.2 \mathrm{t} \\
\text { per/year }\end{array}$ & nothing & $25 / 55$ \\
\hline $\begin{array}{l}\text { Use washing machine for full loads only and dry } \\
\text { hanging your clothes (no tumble dryer) - (saving per } \\
\text { year per household) }\end{array}$ & $\begin{array}{c}0.2 \mathrm{t} \\
\text { per/year }\end{array}$ & nothing & $25 / 55$ \\
\hline $\begin{array}{l}\text { Turn off lighting when leaving rooms - } \\
\text { (saving per year per household) }\end{array}$ & $\begin{array}{c}0.04 \mathrm{t} \\
\text { per/year }\end{array}$ & nothing & $10 / 30$ \\
\hline Taking shorter showers & $\begin{array}{c}0.15 \mathrm{t} \\
\text { per/year }\end{array}$ & nothing & $20 / 40$ \\
\hline \multicolumn{4}{|l|}{ Energy saving product/technology } \\
\hline $\begin{array}{l}\text { Install solid wall insulation - external and internal } \\
\text { (saving per year per household) }\end{array}$ & $\begin{array}{c}1.7 \mathrm{t} \\
\text { per/year }\end{array}$ & $\begin{array}{l}\text { From } 3,750 \\
\text { (5 years) }\end{array}$ & $400 / 600$ \\
\hline $\begin{array}{l}\text { Install floor insulation - } \\
\text { (saving per year per household) }\end{array}$ & $\begin{array}{c}0.3 \mathrm{t} \\
\text { per/year }\end{array}$ & $\begin{array}{l}\text { From } 150 \\
(2 \mathrm{yrs})\end{array}$ & $30 / 60$ \\
\hline $\begin{array}{l}\text { Install solar thermal water heating - } \\
\text { (saving per year per household) }\end{array}$ & $\begin{array}{c}0.3 \mathrm{t} \\
\text { per/year }\end{array}$ & From 4000 & $30 / 60$ \\
\hline $\begin{array}{l}\text { Install solar photovoltaic panels - } \\
\text { (saving per household per year) }\end{array}$ & $\begin{array}{c}1.0 \mathrm{t} \\
\text { per/year }\end{array}$ & From 6,500 & $150 / 200$ \\
\hline $\begin{array}{l}\text { Replace old boiler with more efficient one } \\
\text { (condensing) - } \\
\text { (saving per year per household) }\end{array}$ & $\begin{array}{c}0.8 \mathrm{t} \\
\text { per/year }\end{array}$ & From 2,000 & $75 / 125$ \\
\hline $\begin{array}{l}\text { Install double glazing - } \\
\text { (saving per year per household) }\end{array}$ & $\begin{array}{c}0.7 \mathrm{t} \\
\text { per/year }\end{array}$ & not available & $70 / 110$ \\
\hline $\begin{array}{l}\text { Install a ground source heat pump - } \\
\text { (saving per year per household) }\end{array}$ & $\begin{array}{c}2.0 \mathrm{t} \\
\mathrm{per} / \mathrm{year}\end{array}$ & From 12,000 & $500 / 700$ \\
\hline $\begin{array}{l}\text { Install a micro wind-turbine - } \\
\text { (saving per year per household) }\end{array}$ & $\begin{array}{c}0.6 \mathrm{t} \\
\text { per/year }\end{array}$ & From 1,500 & $75 / 125$ \\
\hline
\end{tabular}


Table A3. Behavioural question example for CT and PCT

The carbon tax is $£(5,10,25)$ per $0.10 \mathrm{t}$ of $\mathrm{CO}_{2}\left(£ 50,100\right.$ or 250 per tonne of $\left.\mathrm{CO}_{2}\right)$ and like everyone you receive a tax refund of $£$ (price multiplied by 4.0 tonnes) at the end of the year.

Your total $\mathrm{CO}_{2}$ tax is Total multiplied by price above ........So, overall you would pay (per year): difference between total tax and tax refund (above)...

Please indicate below what you would do:

(1) I would not reduce my carbon footprint and I would pay the carbon tax for the entire amount

(2) I would reduce my carbon footprint and reduce the amount of tax I would pay

The carbon tax is $£(5,10,25)$ per $0.10 \mathrm{t}$ of $\mathrm{CO}_{2}\left(£ 50,100\right.$ or 250 per tonne of $\left.\mathrm{CO}_{2}\right)$ and everyone receives a tax refund of $£$ (price multiplied by 4.0 tonnes) at the end of the year.

Your total $\mathrm{CO}_{2}$ tax is... Total multiplied by price above .........So, overall your surplus is (per year): .......difference between total tax and tax refund....

Please indicate below what you would do:

(1) I would not reduce my carbon footprint and keep the surplus

(2) I would reduce my carbon footprint and increase the surplus

The extra permits you have may be sold at a price of $£(5,10,25)$ per $0.10 \mathrm{t}$ of $\mathrm{CO}_{2}(£ 50,100$ or 250 per tonne of $\mathrm{CO}_{2}$ )

If you do not change your behaviour you could sell permits and receive (per year): Difference multiplied by price above

Please indicate below what you would do:

(1) I would not reduce my carbon footprint and I would sell the extra carbon permits for the entire amount

(2) I would reduce my carbon footprint and sell more permits

The price for carbon permits above the allowance is $£(5,10,25)$ per $0.10 \mathrm{t}$ of $\mathrm{CO}_{2}(£ 50,100$ or 250 per tonne of $\mathrm{CO}_{2}$ )

If you do not change your behaviour you would need to purchase permits and pay (per year): Difference multiplied by price above

Please indicate below what you would do (question 1):

(1) I would not reduce my carbon footprint and I would buy extra carbon permits for the entire amount

(2) I would reduce my carbon footprint and reduce the amount of permits I would have to purchase 
Table 1. Explanatory variables

\begin{tabular}{|c|c|}
\hline Variable & Coding \\
\hline Male & 1 if respondent is male, 0 if female \\
\hline Base & Respondents more than 60 years old \\
\hline Age1829 & 1 if respondent in the age band $18-29,0$ otherwise \\
\hline Age 3045 & 1 if respondent in the age band $30-45,0$ otherwise \\
\hline Age4560 & 1 if respondent in the age band $45-60,0$ otherwise \\
\hline Hsldsize & Respondent household size \\
\hline Car & 1 if respondent uses a car, 0 otherwise \\
\hline Fly & 1 if respondent flies, 0 otherwise \\
\hline Rent & 1 if respondent live in rented accommodation, 0 otherwise \\
\hline Base & Unemployed respondents \\
\hline Emp & 1 if respondent in full or part time employment, 0 otherwise \\
\hline Educ & 1 if respondent in full or part time education, 0 otherwise \\
\hline Ret & 1 if respondents in retirement, 0 otherwise \\
\hline Taxpct & 1 if respondents faced TAX, 0 if PCT \\
\hline PriceT & Total amount to be paid (or credited) for tax or extra permits \\
\hline PriceU & Amount to be paid (credited) for tax or extra permits per Tonne of $\mathrm{CO}_{2}$ \\
\hline Blwabv & 1 if respondent's initial carbon consumption was below 4.0 tonnes, 0 otherwise \\
\hline Totco 2 & Respondent's initial carbon consumption \\
\hline Base & Gross household income less than $£ 25,000$ \\
\hline Inc 2550 & 1 if gross household income between $£ 25,000$ and $£ 50,000,0$ otherwise \\
\hline Inco $>50$ & 1 if gross household income more than $£ 50,000,0$ otherwise \\
\hline NoInc & 1 if gross household income information missing, 0 otherwise ${ }^{a}$ \\
\hline Lower & 1 if carbon footprint was lower than expected, 0 otherwise \\
\hline Base & No surprise \\
\hline Higher & 1 if carbon footprint was higher than expected, 0 otherwise \\
\hline Base & No current changes in behaviour \\
\hline Chgmon & 1 if existing changes had monetary reasons, 0 otherwise \\
\hline Chgclima & 1 if existing changes had environmental reasons, 0 otherwise \\
\hline Chgother & 1 if existing changes had other reasons, 0 otherwise \\
\hline Costb & Importance score of cost as a barrier to carbon saving actions \\
\hline Timeb & Importance score of time as a barrier to carbon saving actions \\
\hline Easyhome & Perceived ability to reduce carbon emissions from home energy \\
\hline Easytran & Perceived ability to reduce carbon emissions from transport \\
\hline
\end{tabular}


Table 2. Would you reduce given the conditions of the schemes? Binary Logit $-\mathrm{N}=189$

\begin{tabular}{|c|c|c|c|c|}
\hline \multirow[t]{2}{*}{ Variable } & \multicolumn{2}{|l|}{ Model 1} & \multicolumn{2}{|l|}{ Model 2} \\
\hline & B-coeff & T-value & B-coeff & T-value \\
\hline Constant & 0.126 & 0.089 & -1.896 & -1.205 \\
\hline Male & 0.327 & 0.734 & 0.340 & 0.741 \\
\hline Age1829 & -0.369 & -0.482 & -0.166 & -0.215 \\
\hline Age 3044 & -1.216 & $-1.771 *$ & -1.112 & -1.624 \\
\hline Age4560 & -0.993 & -1.421 & -0.928 & -1.323 \\
\hline Hsldsize & 0.397 & $2.278 * *$ & 0.406 & $2.313 * *$ \\
\hline Car & -1.607 & $-2.855 * * *$ & -1.566 & $-2.762 * * *$ \\
\hline Fly & -0.430 & -0.924 & -0.526 & -1.112 \\
\hline Rent & -0.441 & -0.868 & -0.496 & -0.956 \\
\hline Emp & 1.666 & $2.660 * * *$ & 1.535 & $2.451 * *$ \\
\hline Educ & 0.560 & 0.636 & 0.208 & 0.234 \\
\hline Ret & 0.858 & 1.175 & 0.770 & 1.055 \\
\hline Taxpct & 0.808 & $1.860^{*}$ & 0.883 & $2.004 * *$ \\
\hline PriceT & 0.002 & $1.757 *$ & & \\
\hline PriceU & & & 0.011 & $2.489 * *$ \\
\hline Price $\mathrm{T} / \mathrm{U} \times \mathrm{Blwabv}$ & -0.004 & $-1.644 *$ & -0.010 & $-1.647^{*}$ \\
\hline Blwabv & -0.459 & -0.655 & 0.431 & 0.461 \\
\hline Totco 2 & -0.122 & -1.197 & 0.044 & 0.585 \\
\hline Inc 2550 & -0.326 & -0.506 & -0.237 & -0.367 \\
\hline Inc $>50$ & -2.266 & $-2.537 * *$ & -2.067 & $-2.242 * *$ \\
\hline NoInc & -1.031 & $-1.830 *$ & -0.955 & $-1.665^{*}$ \\
\hline Lower & 0.109 & 0.190 & -0.031 & -0.053 \\
\hline Higher & 0.877 & 1.597 & 0.915 & $1.647 *$ \\
\hline Chgmoney & 0.930 & 1.287 & 1.172 & 1.548 \\
\hline Chgclima & 2.091 & $2.652 * * *$ & 2.253 & $2.749 * * *$ \\
\hline Chgother & 1.234 & 1.559 & 1.372 & $1.670^{*}$ \\
\hline Costb & 0.337 & $1.907^{*}$ & 0.320 & $1.776^{*}$ \\
\hline Timeb & -0.433 & $-1.985 * *$ & -0.382 & $-1.744 *$ \\
\hline Easyhome & 0.070 & 0.315 & 0.062 & 0.278 \\
\hline Easytran & 0.254 & 1.274 & 0.242 & 1.194 \\
\hline LogLikelihood & -78.422 & & -77.030 & \\
\hline McFadden $\mathrm{R}^{2}$ & 0.260 & & 0.273 & \\
\hline
\end{tabular}

$*$ Significant at $90 \%$ level - ** $95 \%$ level - *** $99 \%$ level 
Table 3. Average savings per person and composition - tonnes of $\mathrm{CO} 2(\%$ with respect to initial relevant carbon footprint) $\mathrm{N}=189(101 \mathrm{CT}-88 \mathrm{PCT})$

\begin{tabular}{|l|l|l|}
\hline Variable & Scheme & PCT \\
\hline & CT & 5.49 \\
\hline Initial average carbon footprint & 5.62 & \\
\hline Reductions for respondents who saved & & $0.60(15.1)^{\mathrm{a}}$ \\
\hline Transport & $0.27(9.8)^{\mathrm{a}}$ & $0.58(19.3)$ \\
\hline Domestic energy & $0.47(15.3)$ & $1.04(18.6)$ \\
\hline Overall & $0.69(13.9)$ & \\
\hline Reduction for all sample & & $0.45(11.4)^{\mathrm{a}}$ \\
\hline Transport & $0.22(7.7)^{\mathrm{a}}$ & $0.42(13.8)$ \\
\hline Domestic energy & $0.37(12.0)$ & $0.75(13.3)$ \\
\hline Overall & $0.54(10.9)$ & 4.75 \\
\hline Average new carbon footprint (all respondents) & 5.08 & \\
\hline
\end{tabular}

${ }^{a}$ These averages only include respondents who had transport emissions. 
Table 4. How much would you reduce? CO2 savings - GLS - N=142

\begin{tabular}{|c|c|c|c|c|}
\hline Variable & Model 3 & & Model 4 & \\
\hline & B-coeff & T-value & $B$-coeff & T-value \\
\hline Constant & 0.092 & 0.947 & 0.142 & 1.355 \\
\hline Male & 0.002 & 0.069 & 0.003 & 0.104 \\
\hline Age1829 & -0.052 & -1.239 & -0.051 & -1.193 \\
\hline Age3044 & -0.044 & -1.090 & -0.046 & -1.146 \\
\hline Age4560 & -0.022 & -0.632 & -0.020 & -0.548 \\
\hline Hsldsize & -0.017 & $-1.686^{*}$ & -0.015 & -1.518 \\
\hline Car & 0.050 & 1.568 & 0.045 & 1.417 \\
\hline Fly & 0.022 & 0.875 & 0.023 & 0.891 \\
\hline Rent & -0.050 & $-1.648 *$ & -0.051 & $-1.641 *$ \\
\hline Emp & -0.029 & -0.747 & -0.018 & -0.468 \\
\hline Educ & 0.124 & $2.263 * *$ & 0.133 & $2.405 * *$ \\
\hline Ret & -0.023 & -0.516 & -0.016 & -0.367 \\
\hline Taxpct & -0.058 & $-2.172 * *$ & -0.059 & $-2.173 * *$ \\
\hline PriceT & $-0.2 \times 10^{-4}$ & -0.959 & & \\
\hline PriceU & & & $-0.2 \times 10^{-3}$ & -1.040 \\
\hline Price T or U x Blwabv & $0.2 \times 10^{-3}$ & $2.224 * *$ & $0.2 \times 10^{-3}$ & 1.172 \\
\hline Blwabv & -0.024 & -0.564 & -0.034 & -0.594 \\
\hline Totco 2 & 0.001 & 0.150 & -0.004 & -0.847 \\
\hline Inc2550 & 0.001 & 0.038 & -0.009 & -0.268 \\
\hline Inc $>50$ & 0.096 & 1.637 & 0.078 & 1.321 \\
\hline NoInc & 0.081 & $2.307 * *$ & 0.078 & $2.155^{* *}$ \\
\hline Lower & 0.077 & $1.912 *$ & 0.081 & $1.991 * *$ \\
\hline Higher & 0.033 & 1.053 & 0.029 & 0.916 \\
\hline Chgmoney & 0.080 & 1.527 & 0.069 & 1.278 \\
\hline Chgclima & 0.122 & $2.207 * *$ & 0.113 & $1.985 * *$ \\
\hline Chgother & 0.041 & 0.732 & 0.035 & 0.606 \\
\hline Costb & 0.001 & 0.061 & 0.001 & 0.111 \\
\hline Timeb & 0.011 & 0.877 & 0.010 & 0.760 \\
\hline Easyhome & 0.028 & $1.998 * *$ & 0.027 & $1.858^{*}$ \\
\hline Easytran & 0.016 & 1.425 & 0.017 & 1.499 \\
\hline $\mathrm{R}^{2}$ & \multicolumn{2}{|l|}{0.289} & \multicolumn{2}{|l|}{0.272} \\
\hline $\mathrm{Chi}^{2}$ & \multicolumn{2}{|l|}{$80.82(28)^{* * *}$} & \multicolumn{2}{|l|}{$77.48(28) * * *$} \\
\hline
\end{tabular}

* Significant at $90 \%$ level - ** 95\% level - *** 99\% level. 
Figure 1: Partial effects of interaction term for above (ABV) and below (BLW) allocation respondents - PriceT

Figure 2: Partial effects of interaction term for above (ABV) and below (BLW) allocation respondents - PriceU

Figure 3: Partial effects of interaction term for Tax and Pct - PriceT

Figure 4: Partial effects of interaction term for Tax and Pct - PriceU 